\title{
Management of Psychosis in Neuropsychiatric Lupus
}

\author{
Di Kang, Chi Chiu Mok ${ }^{*}$ \\ Department of Medicine, Tuen Mun Hospital, Hong Kong SAR, China
}

\begin{abstract}
Manifestations of neuropsychiatric systemic lupus erythematosus (NPSLE) are heterogeneous. Acute psychosis is an uncommon but well-recognized manifestation of NPSLE. With no specific biomarkers to date, the diagnosis of NPSLE relies on clinical acumen for circumstantial evidence and exclusion of important differential diagnoses. The attribution of psychosis to NPSLE is facilitated by the application attribution models. In particular, the American College of Rheumatology nomenclature, Systemic Lupus International Collaborating Clinics attribution models and Italian algorithm for the attribution of psychosis to NPSLE are revisited. The mainstay of treatment for psychosis attributable to NPSLE is immunosuppression and symptomatic control. In refractory cases, immunomodulatory and emerging biological agents may be considered. This article reviews the diagnostic dilemma, pathogenic mechanisms and treatment of psychosis in SLE patients.
\end{abstract}

Keywords: Systemic Lupus Erythematosus; Neuropsychiatric Lupus; Lupus Psychosis; Corticosteroid-induced Psychosis; Cyclophosphamide; Rituximab.

\section{INTRODUCTION}

Neuropsychiatric (NP) manifestations are common in systemic lupus erythematosus (SLE). The lifetime incidence of neuropsychiatric lupus (NPSLE) among SLE patients was reported to be $9-80 \%$, depending on the definition, diagnostic method and patient selection criteria adopted in the studies [1-3]. Psychosis, albeit an uncommon feature of NPSLE, is a well-recognized syndrome that may lead to significant morbidity. Owing to the lack of specific laboratory or imaging markers for NPSLE, clinical acumen is required to differentiate psychosis as a manifestation of NPSLE from that due to non-SLEortreatment-related causes. Immunosuppression is the mainstay of treatment for psychosis attributable to NPSLE. Immunomodulatory and biological agents may be considered in refractory cases. This article reviews the diagnostic dilemma, pathogenic mechanisms and treatment of psychosis in SLE patients.

\section{NEUROPSYCHIATRIC (NP)} MANIFESTATIONS OF SLE

In 1999, the American College of Rheumatology (ACR) published a set of case definitions for 19 NPSLE syndromes, ranging from overt manifestations such as psychosis, seizure, stroke and myelitis to subtle manifestations such as cognitive dysfunction and peripheral neuropathy (Table 1) [4]. These NP events may concur with lupus flares in other organs or occur in the absence of clinical or serological SLE activity [5], leading to the patient's initial presentation to psychiatrists rather than physicians.

Compared to SLE patients without NP involvement, NPSLE patients tend to have more non-NP manifestations of SLE [6]. Moreover, NP events are associated with reduced health-related quality of life and increased organ damage in SLE patients [7].

According to the European League Against Rheumatism (EULAR) recommendations, the diagnostic workup for NP events in SLE patients should follow that of similar complaints in the general population [8]. In the absence of a diagnostic gold standard for most NPSLE syndromes, the attribution of an NP event to SLE relies on the integration of routine laboratory and immunological tests, cerebrospinal fluid (CSF) analysis, neuropsychological and neuroimaging studies. Stroke and central nervous

( 2019 by the Hong Kong Society of Rheumatology and World Scientific Publishing Co. Pte. Ltd. ə Open Access article under the CC BY-NC-ND license (http://creativecommons.org/licenses/by-nc-nd/4.0/).

Received 13 March 2019; Accepted 28 May 2019; Published 13 June 2019

*Corresponding author: C. C. Mok, Department of Medicine, Tuen Mun Hospital, Tsing Chung Koon Rd, Tuen Mun, Hong Kong, E-mail: ccmok2005@yahoo. com 
Table 1. The ACR nomenclature of neuropsychiatric lupus.

\begin{tabular}{|c|c|}
\hline Diffuse psychiatric syndromes & $\begin{array}{l}\text { - Acute confusional state } \\
\text { - Anxiety disorder } \\
\text { - Cognitive dysfunction } \\
\text { - Mood disorder } \\
\text { - Psychosis }\end{array}$ \\
\hline Central neurological syndromes & $\begin{array}{l}\text { - Aseptic meningitis } \\
\text { - Cerebrovascular disease } \\
\text { - Demyelinating syndrome } \\
\text { - Headache } \\
\text { - Movement disorder } \\
\text { - Myelopathy } \\
\text { - Seizure disorders }\end{array}$ \\
\hline Peripheral neurological syndromes & $\begin{array}{l}\text { - Acute inflammatory demyelinating polyradiculoneuropathy } \\
\text { (Guillain-Barre syndrome) } \\
\text { - Autonomic dysfunction } \\
\text { - Mononeuropathy (simple or multiplex) } \\
\text { - Myasthenia gravis } \\
\text { - Cranial neuropathy } \\
\text { - Plexopathy } \\
\text { - Polyneuropathy }\end{array}$ \\
\hline
\end{tabular}

system (CNS) infections are important differential diagnoses. A chart-based review of 123 NPSLE episodes in two European centers observed that the current clinical practice over-utilized magnetic resonance imaging (MRI) and under-utilized neuropsychological studies (either the 1-hour ACR-SLE battery [9] or the computer-based automated neuropsychological assessment metrics system [10]) for evaluating NP events in SLE patients [11].

\section{PSYCHOSIS AS AN NPSLE MANIFESTATION}

Among the 19 NPSLE syndromes described in the ACR nomenclature [4], psychosis and mood disorders require a clinical evaluation to exclude merely reactive psychological disturbances. The case definition of psychosis attributable to NPSLE follows the terminology of the Diagnostic and Statistical Manual of Mental Disorders, Fourth Edition and falls under the category of 'psychosis due to a general medical condition' (DSMIV 293.81/82) [4].

A population-based validation study for the ACR nomenclature reported that psychosis contributed to merely 5\% of all NP events in Caucasians [2]. On the other hand, psychosis, as defined by the ACR nomenclature, was ranked the fourth most prevalent NPSLE manifestation (11\% of all NP events) in southern Chinese SLE patients [3]. This suggests that the relative prevalence of various NPSLE syndromes may differ across ethnicities.

Psychosis tends to manifest in the early course of SLE, sometimes even as a presenting feature [12]. In a UK cohort, $80 \%$ of the psychotic episodes developed within a year after the formal diagnosis of SLE [13]. More than $50 \%$ of the psychotic episodes attributable to NPSLE involve visual hallucinations. Delusions of grandiosity (35-47\%, depending on the onset of psychosis relative to the diagnosis of SLE) represents the second most common psychotic feature, followed by paranoia (37\%) and auditory hallucinations (18-32\%) [12].

Concomitant depression, anxiety, hypomania and cognitive dysfunction were common [13]. Moreover, psychosis may predict the incidence of other NP events in SLE patients, such as stroke and seizure, in the next five years [12].

\section{AT'TRIBUTION OF PSYCHOSIS TO NPSLE}

Psychosis can occur as a direct consequence of NPSLE, or secondary to organ failure, CNS infections, psychosocial stress and side effect of treatment. Corticosteroidinduced psychosis remains an important differential diagnosis in patients treated recently with corticosteroid. The attribution of psychosis to NPSLE poses a clinical challenge and may be facilitated by the application of attribution models (summarized in Table 2). 
Table 2. Summary of the commonly used models for the attribution of a NP event to NPSLE*

\begin{tabular}{|c|c|c|c|}
\hline & \multirow[t]{2}{*}{$\begin{array}{l}\text { American College of } \\
\text { Rheumatology nomenclature } \\
\text { (1999) }\end{array}$} & $\begin{array}{l}\text { Systemic lupus international } \\
\text { collaborating clinics attribution models } \\
\text { (2007) }\end{array}$ & \multirow[t]{2}{*}{$\begin{array}{l}\text { Italian Society of Rheumatology } \\
\text { attribution model (2015) }\end{array}$} \\
\hline & & Model B & \\
\hline $\begin{array}{l}\text { Decision } \\
\text { rules }\end{array}$ & $\begin{array}{l}\text { 1) Presence of delusions and/or } \\
\text { hallucinations without insight; } \\
\text { 2) Presence of functional } \\
\text { impairment as a consequence; } \\
\text { 3) Absence of delirium; } \\
\text { 4) Absence of secondary causes or } \\
\text { conditions primarily associated } \\
\text { with psychosis }\end{array}$ & $\begin{array}{l}\text { 1) Time of onset of the NP event in } \\
\text { relation to the diagnosis of SLE; } \\
\text { 2) Presence of concurrent non-SLE factors } \\
\text { thought to be a significant contributor } \\
\text { to the NP event; } \\
\begin{array}{ll}\text { 3) Type of NP event } & \text { ***. } \\
\text { Allowed an onset of } & \text { Allowed an onset } \\
\text { NP events } & \text { of NP events } \\
6 \text { months prior } & \text { up to } 10 \text { years } \\
\text { to the diagnosis } & \text { prior to the } \\
\text { of SLE. } & \text { diagnosis of }\end{array}\end{array}$ & $\begin{array}{l}\text { 1) Time of onset of the NP event in } \\
\text { relation to the diagnosis of SLE: } \\
\text { (a) Before }-0 \text { points } \\
\text { (b) Concomitant }-3 \text { points } \\
\text { (c) After }-2 \text { points; } \\
\text { 2) Type of NP event*** } \\
\text { (a) Major }-3 \text { points } \\
\text { (b) Minor }-0 \text { points; } \\
\text { 3) Presence of confounding non-SLE } \\
\text { factors that may contribute to the } \\
\text { NP event: } \\
\text { (a) None }-2 \text { points } \\
\text { (b) One - } 1 \text { point } \\
\text { (c) More than one - } 0 \text { points; } \\
\text { 4) Presence of additional factors } \\
\text { favoring an attribution to SLE**** } \\
\text { (a) None }-0 \text { points } \\
\text { (b) One }-1 \text { point } \\
\text { (c) More than one }-2 \text { points. }\end{array}$ \\
\hline $\begin{array}{l}\text { Clinical } \\
\text { significance }\end{array}$ & $\begin{array}{l}\text { 1) The ACR nomenclature was } \\
\text { the first set of standard case } \\
\text { definitions and diagnostic } \\
\text { criteria for NPSLE. } \\
\text { 2) NP events were divided } \\
\text { into three domains: diffuse } \\
\text { psychiatric, central neurological } \\
\text { and peripheral neurological } \\
\text { syndromes. } \\
\text { 3) The case definitions for anxiety, } \\
\text { mood disorder and psychosis } \\
\text { required an exclusion of reactive } \\
\text { psychological disturbances. } \\
\text { The case definition for lupus } \\
\text { psychosis followed the DSM- } \\
\text { IV entity "psychosis due to a } \\
\text { general medical condition". }\end{array}$ & $\begin{array}{l}\text { 1) The SLICC models covered 'minor' } \\
\text { neuropsychiatric events }{ }^{* *} \text { that were } \\
\text { previously excluded from the ACR } \\
\text { nomenclature. } \\
\text { 2) Model A allowed a small enrollment } \\
\text { window to capture neuropsychiatric } \\
\text { events most probably attributable } \\
\text { to NPSLE. Model B included } \\
\text { neuropsychiatric events occurring long } \\
\text { before the formal diagnosis of SLE to } \\
\text { cover more neuropsychiatric events } \\
\text { possibly attributable to NPSLE. }\end{array}$ & $\begin{array}{l}\text { 1) A numerical score ranging } 0-10 \text { was } \\
\text { introduced, recognizing that the } \\
\text { attribution of psychosis to NPSLE } \\
\text { represented a continuous spectrum } \\
\text { of likelihoods, rather than a discrete } \\
\text { classification. } \\
\text { 2) The Italian algorithm correctly } \\
\text { attributed psychosis and anxiety } \\
\text { disorder to NPSLE with a specificity } \\
\text { of } 100 \% \text {. }\end{array}$ \\
\hline
\end{tabular}

Differentiating SLE-related psychosis from non-SLE-related psychosis

The ACR nomenclature of psychosis as an NPSLE manifestation requires the satisfaction of four criteria: (1) the presence of delusions and/or hallucinations without insight; (2) the presence of functional impairment as a consequence; (3) the absence of delirium; and (4) the absence of secondary causes (e.g. concomitant neurological disorder) or conditions primarily associated with psychosis (e.g. schizophrenia) 
[4]. While the ACR nomenclature marked the first step towards a standard set of case definitions for NPSLE, it was established to characterize an NP event in objectified terms rather than to classify the event as lupus in origin.

The Systemic Lupus International Collaborating Clinics (SLICC) attribution model was introduced in 2007 to guide the diagnosis of NPSLE [7]. Patients with either 'major' or 'minor' NP events, as defined by Ainiala et al. [14], were included. 'Minor' NP events, such as headache, anxiety, depression, cognitive dysfunction and polyneuropathy, were previously excluded from the ACR nomenclature because they occurred frequently in the general population and were deemed less specific for NPSLE [14]. Despite the extended scope of manifestations covered, psychosis remained a key NPSLE syndrome in the SLICC model.

The SLICC recommended the occurrence of a 'minor' NP event, presence of at least one confounding non-SLE factor, or onset outside of the enrollment window (6 months prior to the diagnosis of SLE [model A]; or 10 years prior to the diagnosis of SLE [model B]) favored the attribution of an NP event to nonNPSLE causes [7]. The more stringent model A allowed a smaller enrollment window to capture NP events most probably attributable to NPSLE, whereas the less stringent model B included NP events which occurred within 10 years before in view of the observed that lupus manifestations and autoantibodies could be present up to a decade prior to the formal diagnosis of SLE [15]. Depending on the model adopted, $19-38 \%$ of the NP events were attributed to NPSLE. In an independent prospective validation study, model A demonstrated an excellent specificity of $98 \%$ and poor sensitivity of $33 \%$, while model B demonstrated a satisfactory specificity of $86 \%$ and fair sensitivity of $64 \%$ [16]. The intermodel discrepancy revealed the impact of altering the stringency of the decision rules. Including NP events occurring long before the diagnosis of SLE rendered their attribution to NPSLE less specific.

In 2015, the Italian Society of Rheumatology modified the SLICC model and introduced a new attribution algorithm [17]. A numerical score ranging from 0 to 10 was calculated from four weighted items: (1) the time of onset of the NP event (before, concomitant with, or after the diagnosis of SLE); (2) the type of NP event ('major' or 'minor', as defined by Ainiala et al. [14]); (3) the presence of confounding non-SLE factors (e.g. concurrent sepsis or disseminated malignancy); (4) the presence of factors favoring an attribution to
SLE (e.g. high systemic lupus activity). When validated against the clinical judgment of a blinded expert assessor team, a total score $\geq 7$ attributed $82.9 \%$ of the NP events to NPSLE correctly with a sensitivity of $71.2 \%$ and specificity of $84.5 \%$ [18]. In particular, the Italian algorithm attributed psychosis and anxiety disorder to NPSLE correctly with a specificity of 100\% [19].

Differentiating lupus psychosis from corticosteroidinduced psychosis

Adverse psychiatric reaction to corticosteroid is an important differential diagnosis of lupus psychosis. Adverse psychiatric reactions are observed in 3-10\% patients receiving corticosteroid [20]. The most commonly reported symptom is euphoria [20]. Psychotic features, such as visual and auditory hallucinations, delusions of grandiosity and paranoia, alteration in behavior and cognitive impairment may occur in both lupus psychosis and corticosteroid-induced psychosis [20,21].

Corticosteroid-induced psychosis emerges within 8 weeks of corticosteroid administration [20], most commonly with a prednisolone-equivalent dose $\geq 80 \mathrm{mg} /$ day [21] or in patients with serum albumin $<25 \mathrm{~g} / \mathrm{L}$ [22]. The increased risk of corticosteroidrelated adverse events in general medical patients with hypoalbuminemia was first reported in 1971 [22]. More recently, a local prospective cohort study identified hypoalbuminemia as the only independent predictor for adverse psychiatric reactions to corticosteroid in Chinese SLE patients, after adjusting for personal or family history of psychiatric disorders, corticosteroid regime and routine laboratory findings [20]. The mechanism by which hypoalbuminemia precipitates corticosteroid-induced steroid psychosis is unknown. A popular postulation is that synthetic corticosteroid binds to albumin; therefore the concentration of free, biologically active form of synthetic corticosteroid depends on the serum albumin level [23]. Noteworthy is that patients with lupus nephritis are more likely to have hypoalbuminemia and to receive high-dose corticosteroid, rendering them more susceptible to corticosteroid-induced psychosis.

The differentiation between lupus psychosis and corticosteroid-induced psychosis is crucial because entirely different treatments are indicated. The former requires an escalation of immunosuppressive treatment whereas the latter requires a dose reduction of corticosteroid. A trial of corticosteroid reduction 
is advisable when psychosis develops shortly after the initiation of high-dose corticosteroid. Corticosteroidinduced psychotic episodes usually resolve within 2 weeks after the trial [24]. In patients with a history of corticosteroid-induced psychosis, a high level of clinical vigilance, reduced dosage and early use of corticosteroidsparing agents are recommended when corticosteroid is indicated in the future.

\section{PROPOSED MECHANISMS OF NPSLE}

Vasculopathy is a popular proposed mechanism for NPSLE. Both small and large vessel insults have been observed in histopathological studies. Postmortem examination of the brain of SLE patients found microinfarcts and microvascular lesions, suggesting the CNS damage in SLE might be inflicted by small vessel occlusions [25]. A more recent postmortem study observed that the histopathological lesions of NPSLE represented a continuum from non-specific focal lesions and microthrombi specifically associated with complement deposition to diffuse vasculitis and macroinfarction [26]. Histological evidence of microvascular injury often located in the vicinity of white matter hyperintensities on paired ex vivo MRI [26]. Meanwhile, large vessel vasculitic changes were identified on the cerebral angiogram $[27,28]$, and a diffuse reduction in brain perfusion was seen on the functional brain MRI of NPSLE patients [13].

During an inflammatory episode, perivascular accumulation of mononuclear cells and cytokines either in the systemic circulation or CNS may disrupt the blood brain barrier, allowing the passage of autoantibodies into the CNS [29,30]. Autoantibody deposition leads to neurotoxicity and glial cell activation, thereby producing an abundance of cytokines in the CNS and perturbing normal neuronal function. More than 20 autoantibodies have been identified in NPSLE patients, which may account for the heterogeneity of their manifestations [29,31]. For instance, anti-ribosomal P was associated with psychiatric (with a strong predilection to psychosis) but not neurological manifestations of NPSLE [32-35]. Anti-ribosomal $\mathrm{P}$ recognizes a neuronal surface antigen preferentially distributed in areas involved in memory, cognition and emotion. High titers of the antibody were recorded in full-blown psychosis [36]. On the other hand, the antibodies to NR2 subunit of N-methyl d-aspartate receptor (anti-NR2 antibodies) received recent attention for its association with diffuse cerebral dysfunction, such as cognitive impairment and depression, in 6 out of 13 cohort studies [37]. Animal studies demonstrated that anti-NR2 antibodies may inflict neuronal cell apoptosis, hippocampal and amygdala atrophy upon their entry to the CNS [37]. Future research on the association between the autoantibodies and types of NP events may identify novel biomarkers for predicting the incidence of specific NPSLE syndromes.

In addition to the inflammatory mechanism, autoantibodies may also mediate the ischemic mechanism of NPSLE. The renowned antiphospholipid antibodies were associated with thrombosis and found in $10 \%$ of the NPSLE patients [13]. Passive immunization with monoclonal human anticardiolipin antibodies led to NP events in mice [38]. Apart from triggering vascular thrombosis, the antiphospholipid antibodies interact with the neurotransmitter receptors, perturb the inflammatory cytokines in the CNS and alter the synaptoneurosomes [39].

\section{PHARMACOLOGICAL TREATMENT OF}

\section{LUPUS PSYCHOSIS}

Based on the presumptive pathogenic mechanisms, various combinations of immunosuppressive, anticoagulant and symptomatic treatments are adopted for NPSLE. Immunosuppressive treatment should be initiated after non-SLE related causes of psychosis are excluded. Immunomodulatory therapies are commonly adopted for augmentation in refractory cases even though their efficacy is unproven.

\section{Immunosuppressive treatment}

Intravenous (IV) methylprednisolone (MP), at a dose of $1 \mathrm{~g} /$ day for 3-5 days, is the standard treatment for acute NPSLE as it offers a rapid anti-inflammatory effect. Oral prednisolone typically follows with a tapering scheme over 3 to 12 months.

If the NPSLE syndrome shows poor response to a 7-day course of high-dose corticosteroid, or is accompanied by severe neurological symptoms, such as optic neuritis or refractory seizures, evidence of CNS inflammation in CSF analysis or on brain MRI, the addition of IV cyclophosphamide (CYC) is recommended after the exclusion of non-SLE causes [40]. This Cochrane recommendation was based on a single controlled trial comparing the efficacy of IV CYC as an isolated therapy against IV MP in 32 NPSLE patients [41]. Over $90 \%$ of the patients in the CYC group showed significant improvement in clinical or laboratory measures, compared to $<50 \%$ 
in the MP group. The incidence of side effects, such as infections, hyperglycemia and hypertension, did not differ significantly between the two groups. Moreover, CYC use was associated with a reduction in long-term prednisolone requirement [40]. While the recommendation was only supported by low-quality evidence, the combination of IV MP and CYC for severe NPSLE is a common practice in our locality.

The use of oral CYC for lupus psychosis was explored in an open-label study from our group, which observed that prednisolone (mean dose \pm standard deviation 1.1 $\pm 0.2 \mathrm{mg} / \mathrm{kg} / \mathrm{d}$, tapered after 8 weeks to $5-10 \mathrm{mg} / \mathrm{d}$ ) combined with sequential oral CYC $(1.6 \pm 0.7 \mathrm{mg} / \mathrm{kg} / \mathrm{d}$ for a mean duration of 5.4 months) and maintenance azathioprine (AZA) $(1.8 \pm 0.8 \mathrm{mg} / \mathrm{kg} / \mathrm{d}$ indefinitely), was associated with a high remission rate of $92.3 \%$ over a mean follow-up period of 86 months [1]. This suggests that the regimen of sequential oral CYC induction and AZA maintenance is effective in controlling lupus psychosis and has a corticosteroid-sparing potential.

Maintenance therapy is often indicated in NPSLE after successful control of the acute episode. AZA, mycophenolate mofetil and cyclosporin A are commonly used for maintenance with observed corticosteroidsparing effects, even though their specific efficacy for NPSLE has not been established by randomized controlled trials (RCT) [42].

\section{Immunomodulatory therapy}

IV immunoglobulin (IG) contains IgG antibodies derived from the blood of healthy donors and is believed to modulate immunity by enhancing the activity of regulatory $\mathrm{T}$ cells, neutralizing pathogenic autoantibodies and suppressing autoantibody production by B cells $[43,44]$. IVIG is often used at a dose of $0.4 \mathrm{mg} / \mathrm{kg} /$ day for 5 days when the NPSLE syndrome does not respond to standard immunosuppressive treatment or when immunosuppressive treatment is contraindicated in the presence of severe concurrent infection. While rapid beneficial effects have been observed with a trial of IVIG, its use has not been compared against standard immunosuppressive treatments by RCT. The side effects of IVIG, such as flu-like symptoms, are mostly mild and self-limiting. Thromboembolism has been reported in isolated cases of elderly patients with multiple vascular risk factors [45]. IVIG is safe in pregnancy [45].

Plasma exchange provides another option for modulating the humoral immune response.
Autoantibodies are removed directly by passing venous blood through an extracorporeal continuous flow centrifugation device. In a systematic review of 26 patients with NPSLE, 74\% showed improvement after plasma exchange alone or in combination with CYC [46]. A retrospective study showed that the adjunction of plasma exchange led to complete remission in 7 out of 13 patients and partial remission in the remaining 6 patients [47]. Most side effects of plasma exchange are related to central line insertion rather than immunomodulation [46]. Citrate-containing solution for anticoagulation imposes a risk of citrate-induced hypocalcemia and metabolic alkalosis [48,49]. Plasma exchange also produces a transient decrease in blood coagulation factors, predisposing to rare bleeding episodes [50]. Similar to IVIG, patients were receiving simultaneous immunosuppressive treatment in most of the successful cases reported with plasma exchange. The efficacy of plasma exchange for refractory NPSLE awaits evaluation by RCT. In addition, the clinical utility of plasma exchange is limited by its procedural complexity and equipment cost.

\section{EMERGING BIOLOGICAL THERAPY}

Owing to the inflammatory pathogenic mechanism, targeted immunosuppressive agents are optimistic candidates for refractory NPSLE. Rituximab (RTX), a chimeric anti-CD20 monoclonal antibody, is an established option for treating lymphoid malignancies but relatively novel in the realm of SLE pharmacotherapy [51]. A course of RTX suppresses the level of CD20+ B cells for up to 6 months [52,53]. The combination of CYC and RTX led to a pronounced fall in anti-ribosomal P antibodies, followed by clinical remission, in an isolated case report [54]. In a case series of NPSLE refractory to conventional immunosuppressive treatment and plasma exchange, the use of RTX led to clinical response in all of the 10 patients [52]. A significant improvement in the SLE Disease Activity Index (SLEDAI) and cerebral perfusion on functional brain MRI were also observed [52]. A systematic review of 21 case reports and uncontrolled studies concluded that RTX, as an add-on therapy, resulted in complete or partial response in $85 \%$ of refractory NPSLE with a median time to remission of 9.5 months. However, relapse was recorded in $45 \%$ of the patients upon the cessation of RTX, suggesting that maintenance RTX may be necessary [55]. Infection was common after RTX use, yet no severe infusion reactions or hematological abnormalities were reported [52]. Owing 
to the lack of RCT on the efficacy of RTX for refractory NPSLE, its use for this purpose is off-label in our locality. The appropriate dosing schedule of RTX and need for combining RTX with MP or CYC for optimal disease control remain to be determined by further studies.

Besides auto-reactive $\mathrm{B}$ cells, pro-inflammatory cytokines is a major culprit for the disruption of bloodbrain barrier and penetration of autoantibodies to the CNS. Anifrolumab, a type I interferon receptor $\alpha / \beta$ antagonist, achieved a marked reduction in disease activity ( $\geq 4$ points on the SLEDAI) over 6 months and a sustained corticosteroid-sparing effect in adults with moderate-to-severe SLE in a recent phase IIB trial [56]. A greater effect size was observed in patients with a higher interferon gene signature at baseline. Herpes zoster and influenza were more frequent in the anifrolumab-treated patients than controls [56]. Anifrolumab is currently in phase III clinical trial for treating SLE; however, patients with severe NPSLE are excluded.

The Janus kinase-signal transducer and activator of transcription (JAK-STAT) pathway is the major downstream signaling cascade of type I and type II cytokine receptors. Tofacitinib, a JAK1/JAK3 inhibitor, is able to block this cascade effectively and has been approved for the treatment of rheumatoid arthritis. While a reduction in proteinuria and serum creatinine levels and mild improvement in endothelium-dependent vasorelaxation were observed in the tofacitinib-treated mice [57]. Tofacitinib is currently in phase II trial for treating SLE-associated vasculopathy. Further understanding on the pathogenic role of autoantibodies and cytokines in NPSLE is expected to give rise to an abundance of targeted biological agents for treating specific subtypes of NPSLE.

\section{Antithrombotic therapy}

In SLE patients with antiphospholipid antibodies and a history of thromboembolism, long-term warfarin is indicated [58]. Hydroxychloroquine, a commonly used antimalarial for reducing lupus activity, has been shown to reduce the risk of cerebrovascular accidents and transient ischemic attacks (HR 0.28, 95\% CI 0.08-0.90) in a Spanish prospective cohort study [59].

\section{Symptomatic psychiatric treatment}

Whereas immunosuppressive and immunomodulatory therapies are used to treat the underlying NPSLE, psychiatric medications are required for immediate symptom control. Risperidone and olanzapine are commonly used antipsychotic agents in our locality. Antidepressant and anxiolytic agents are indicated in patients with concomitant depressive or anxious symptoms [13].

Dystonia and dyskinesia are well-known side effects of antipsychotic agents. Long-term use of antipsychotic agents is also associated with metabolic derangement, brain volume reduction and global cognitive decline [60-63]. In most patients with psychosis attributable to NPSLE, prolonged use of antipsychotic agents is unnecessary as most symptoms resolve in $2-4$ weeks with appropriate immunosuppressive treatment.

\section{LONG-TERM PROGNOSIS OF LUPUS PSYCHOSIS}

The long-term outlook of psychosis as an NPSLE manifestation is favorable. After 1 year of appropriate treatment, $60 \%$ psychosis attributable to NPSLE showed complete remission for up to a decade in the UK cohort [13]. Interestingly, the patients showing sustained remission were those who received the most aggressive immunosuppressive treatment in their acute episode [13]

\section{CONCLUSION}

NPSLE continues to pose diagnostic challenges to clinicians. Comparative studies are needed to validate the performance of various attribution models and unify the criteria for NPSLE.

A widerange of pathogenic mechanisms mayunderlie the heterogeneous NPSLE manifestations. Enhanced histopathological, neuroimaging and symptomatic correlation may facilitate the characterization of NPSLE manifestations beyond a syndromal level and shed light for further development of therapeutic agents targeting specific subtypes of NPSLE.

\section{REFERENCES}

[1] Mok C, Lau C, Wong R. Treatment of lupus psychosis with oral cyclophosphamide followed by azathioprine maintenance: an open-label study. Am J Med. 2003;115(1):59-62.

[2] Brey R, Holliday S, Saklad A, Navarrete M, Hermosillo-Romo D, Stallworth C, et al. Neuropsychiatric syndromes in lupus. Neurology. 2002;58(8):1214-20.

[3] Mok C, Lau C, Wong R. Neuropsychiatric manifestations and their clinical associations in southern Chinese patients with systemic lupus erythematosus. J Rheumatol. 2001;28(4):766-71.

[4] The American College of Rheumatology nomenclature and case definitions for neuropsychiatric lupus syndromes. Arthritis Rheum. 1999;42(4):599-608. 
[5] Winfield J, Brunner C, Koffler D. Serologic studies in patients with systemic lupus erythematosus and central nervous system dysfunction. Arthritis Rheum. 1978;21(3):289-94.

[6] Abel T, Gladman D, Urowitz M. Neuropsychiatric lupus. J Rheumatol. 1980;7:325-33.

[7] Hanly J, Urowitz M, Sanchez-Guerrero J, Bae S, Gordon C, Wallace D, et al. Neuropsychiatric events at the time of diagnosis of systemic lupus erythematosus: an international inception cohort study. Arthritis Rheum. 2007;56(1):265-73.

[8] Bertsias G, Ioannidis J, Boletis J, Bombardieri S, Cervera R, Dostal C, et al. EULAR recommendations for the management of systemic lupus erythematosus. Report of a Task Force of the EULAR Standing Committee for International Clinical Studies Including Therapeutics. Ann Rheum Dis. 2007;67(2): 195-205.

[9] Kozora E, Ellison M, West S. Reliability and validity of the proposed American College of Rheumatology neuropsychological battery for systemic lupus erythematosus. Arthritis Rheum. 2004;51(5):810-8.

[10] Kane R, Roebuckspencer T, Short P, Kabat M, Wilken J. Identifying and monitoring cognitive deficits in clinical populations using Automated Neuropsychological Assessment Metrics (ANAM) tests. Arch Clin Neuropsych. 2007;22: 115-26.

[11] Pamfil C, Fanouriakis A, Damian L, Rinzis M, Sidiropoulos P, Tsivgoulis G, et al. EULAR recommendations for neuropsychiatric systemic lupus erythematosus vs usual care: results from two European centres. Rheumatology. 2015;54(7):1270-8.

[12] Appenzeller S, Cendes F, Costallat L. Acute psychosis in systemic lupus erythematosus. Rheumatol Int. 2008;28(3):237-43.

[13] Pego-Reigosa J, Isenberg D. Psychosis due to systemic lupus erythematosus: characteristics and long-term outcome of this rare manifestation of the disease. Rheumatology. 2008;47(10):1498-1502.

[14] Ainiala H, Hietaharju A, Loukkola J, Peltola J, Korpela M, Metsänoja R et al. Validity of the new American College of Rheumatology criteria for neuropsychiatric lupus syndromes: a population-based evaluation. Arthritis Rheum. 2001;45(5): 419-23.

[15] Arbuckle M, McClain M, Rubertone M, Scofield R, Dennis G, James J, et al. Development of autoantibodies before the clinical onset of systemic lupus erythematosus. N EnglJ Med. 2003;349(16):1526-33.

[16] Magro-Checa C, Zirkzee E, Beaart-van de Voorde L, Middelkoop $\mathrm{H}$, van der Wee N, Huisman M, et al. Value of multidisciplinary reassessment in attribution of neuropsychiatric events to systemic lupus erythematosus: prospective data from the Leiden NPSLE cohort. Rheumatology. 2017;56(10):1676-83.

[17] Bortoluzzi A, Scirè C, Bombardieri S, Caniatti L, Conti F, De Vita $S$ et al. Development and validation of a new algorithm for attribution of neuropsychiatric events in systemic lupus erythematosus. Rheumatology. 2014;54(5):891-8.

[18] Bortoluzzi A, Fanouriakis A, Appenzeller S, Costallat L, Scirè C, Murphy E, et al. Validity of the Italian algorithm for the attribution of neuropsychiatric events in systemic lupus erythematosus: a retrospective multicentre international diagnostic cohort study. BMJ Open. 2017;7(5):e015546.
[19] Bortoluzzi A, Scirè CA, Govoni M. Attribution of neuropsychiatric manifestations to systemic lupus erythematosus. Front Med. 2018;5.

[20] Chau S, Mok C. Factors predictive of corticosteroid psychosis in patients with systemic lupus erythematosus. Neurology. 2003;61(1):104-7.

[21] Wolkowitz O, Burke H, Epel E, Reus V. Glucocorticoids. Ann NY Acad Sci. 2009;1179(1):19-40.

[22] Lewis G, Jusko W, Burke C, Graves L. Prednisone side-effects and serum-protein levels. Lancet. 1971;298(7728):778-81.

[23] Lopez-Medrano F. Corticosteroid induced psychosis in systemic lupus erythematosus: a possible role of serum albumin level. Ann Rheum Dis. 2002;61(6):562-3.

[24] Sirois F. Steroid psychosis: a review. Gen Hosp Psychiatry. 2003;25(1):27-33.

[25] Bodani M, Kopelman M. A psychiatric perspective on the therapy of psychosis in systemic lupus erythematosus. Lupus. 2003;12(12):947-9.

[26] Cohen D, Rijnink EC, Nabuurs RJA, Steup-Beekman GM, Versluis MJ, Emmer BJ, et al. Brain histopathology in patients with systemic lupus erythematosus: identification of lesions associated with clinical neuropsychiatric lupus syndromes and the role of complement. Rheumatology. 2016;56(1):77-86.

[27] Weiner D, Allen N. Large vessel vasculitis of the central nervous system in systemic lupus erythematosus: report and review of the literature. J Rheumatol. 1991;18(5):748-51.

[28] Böckle BC, Jara D, Aichhorn K, Junker D, Berger T, Ratzinger $\mathrm{G}$, et al. Cerebral large vessel vasculitis in systemic lupus erythematosus. Lupus. 2014;23(13):1417-21.

[29] Katzav A, Ben-Ziv T, Blank M, Pick C, Shoenfeld Y, Chapman J. Antibody-specific behavioral effects: Intracerebroventricular injection of antiphospholipid antibodies induces hyperactive behavior while anti-ribosomal-P antibodies induces depression and smell deficits in mice. J Neuroimmunol. 2014;272(1-2): 10-5.

[30] Wen J, Stock A, Chalmers S, Putterman C. The role of B cells and autoantibodies in neuropsychiatric lupus. Autoimmun Rev. 2016;15(9):890-5.

[31] Muscal E, Myones B. The role of autoantibodies in pediatric neuropsychiatric systemic lupus erythematosus. Autoimmun Rev. 2007;6(4):215-7.

[32] Katzav A, Solodeev I, Brodsky O, Chapman J, Pick C, Blank M, et al. Induction of autoimmune depression in mice by antiribosomal $\mathrm{P}$ antibodies via the limbic system. Arthritis Rheum. 2007;56(3):938-48.

[33] Abdel-Nasser A, Ghaleb R, Mahmoud J, Khairy W, Mahmoud R. Association of anti-ribosomal $\mathrm{P}$ protein antibodies with neuropsychiatric and other manifestations of systemic lupus erythematosus. Clin Rheumatol. 2008;27(11):1377-85.

[34] Hanly J, Urowitz M, Siannis F, Farewell V, Gordon C, Bae S, et al. Autoantibodies and neuropsychiatric events at the time of systemic lupus erythematosus diagnosis: results from an international inception cohort study. Arthritis Rheum. 2008;58(3):843-53.

[35] Bonfa E, Golombek SJ, Kaufman LD, Skelly S, Weissbach H, Brot $\mathrm{N}$, et al. Association between lupus psychosis and anti-ribosomal p protein antibodies. N Engl J Med. 1987;317(5):265-71. 
[36] Matus S, Burgos P, Bravo-Zehnder M, Kraft R, Porras O, Farías $\mathrm{P}$, et al. Antiribosomal-P autoantibodies from psychiatric lupus target a novel neuronal surface protein causing calcium influx and apoptosis. J Exp Med. 2007;204(13):3221-34.

[37] Lauvsnes MB, Omdal R. Systemic lupus erythematosus, the brain, and anti-NR2 antibodies. J Neurol. 2011;259(4):622-9.

[38] Katzav A, Shoenfeld Y, Chapman J. The pathogenesis of neural injury in animal models of the antiphospholipid syndrome. Clin Rev Allergy Immunol. 2009;38(2-3):196-200.

[39] Rege S, Mackworth-Young C. Antiphospholipid antibodies as biomarkers in psychiatry: review of psychiatric manifestations in antiphospholipid syndrome. Transl Dev Psychiatry. 2015;3(1):25452.

[40] Fernandes Moça Trevisani V, Castro A, Ferreira Neves Neto J, Atallah Á. Cyclophosphamide versus methylprednisolone for treating neuropsychiatric involvement in systemic lupus erythematosus. Cochrane Database Sys Rev. 2013;28(2).

[41] Barile-Fabris L. Controlled clinical trial of IV cyclophosphamide versus IV methylprednisolone in severe neurological manifestations in systemic lupus erythematosus. Ann Rheum Dis. 2005;64(4):620-5.

[42] Magro-Checa C, Zirkzee E, Huizinga T, Steup-Beekman G. Management of neuropsychiatric systemic lupus erythematosus: current approaches and future perspectives. Drugs. 2016;76(4): 459-83.

[43] Costa N, Pires AE, Gabriel AM, Goulart LF, Pereira C, Leal B, et al. Broadened T-cell repertoire diversity in ivIg-treated SLE patients is also related to the individual status of regulatory T-cells. J Clin Immunol. 2012;33(2):349-60.

[44] Bayry J, Negi V, Kaveri S. Intravenous immunoglobulin therapy in rheumatic diseases. Nat Rev Rheumatol. 2011;7(6):349-59.

[45] Katz U, Achiron A, Sherer Y, Shoenfeld Y. Safety of intravenous immunoglobulin (IVIG) therapy. Autoimmun Rev. 2007;6(4):257-9.

[46] Neuwelt C. The role of plasmapheresis in the treatment of severe central nervous system neuropsychiatric systemic lupus erythematosus. Ther Apher Dial. 2003;7(2):173-82.

[47] Bartolucci P, Bréchignac S, Cohen P, Le Guern V, Guillevin L. Adjunctive plasma exchanges to treat neuropsychiatric lupus: a retrospective study on 10 patients. Lupus. 2007;16(10):817-22.

[48] Weinstein R. Prevention of citrate reactions during therapeutic plasma exchange by constant infusion of calcium gluconate with the return fluid. J Clin Apher. 1996;11(4):204-10.

[49] Pearl RG, Rosenthal MH. Metabolic alkalosis due to plasmapheresis. Am J Med. 1985;79(3):391-3.

[50] Chirnside A, Urbaniak SJ, Prowse CV, Keller AJ. Coagulation Abnormalities following Intensive Plasma Exchange on the Cell Separator. Br J Haematol. 2008;48(4):627-34.

[51] Salles G, Barrett M, Foà R, Maurer J, O’Brien S, Valente N, et al. Rituximab in B-cell hematologic malignancies: a review of 20 years of clinical experience. Adv Ther. 2017;34(10):2232-73.
[52] Tokunaga M, Fujii K, Saito K, Nakayamada S, Tsujimura S, Nawata M, et al. Down-regulation of CD40 and CD80 on B cells in patients with life-threatening systemic lupus erythematosus after successful treatment with rituximab. Rheumatology. 2004;44(2):176-82.

[53] Tokunaga M, Saito K, Kawabata D, Imura Y, Fujii T, Nakayamada S, et al. Efficacy of rituximab (anti-CD20) for refractory systemic lupus erythematosus involving the central nervous system. Ann Rheum Dis. 2006;66(4):470-5.

[54] Karsten Conrad N. Antibodies to ribosomal P in lupus psychosis resolving after rituximab plus cyclophosphamide - a case report. J Clin Cell Immunol. 2013;04(05).

[55] Narváez J, Ríos-Rodriguez V, de la Fuente D, Estrada P, LópezVives L, Gómez-Vaquero C, et al. Rituximab therapy in refractory neuropsychiatric lupus: current clinical evidence. Semin Arthritis Rheu. 2011;41(3):364-72.

[56] Furie R, Khamashta M, Merrill J, Werth V, Kalunian K, Brohawn $\mathrm{P}$, et al. Anifrolumab, an anti-interferon-a receptor monoclonal antibody, in moderate-to-severe systemic lupus erythematosus. Arthritis Rheum. 2017;69(2):376-86.

[57] Furumoto Y, Smith C, Blanco L, Zhao W, Brooks S, Thacker S, et al. Tofacitinib ameliorates murine lupus and its associated vascular dysfunction. Arthritis Rheum. 2016;69(1):148-60.

[58] Bala M, Celinska-Lowenhoff M, Szot W, Padjas A, Kaczmarczyk M, Swierz M, et al. Antiplatelet and anticoagulant agents for secondary prevention of stroke and other thromboembolic events in people with antiphospholipid syndrome. Cochrane Database Sys Rev. 2017 Oct;2(10).

[59] Ruiz-Irastorza G, Egurbide M, Pijoan J, Garmendia M, Villar I, Martinez-Berriotxoa A, et al. Effect of antimalarials on thrombosis and survival in patients with systemic lupus erythematosus. Lupus. 2006;15(9):577-83.

[60] Husa A, Moilanen J, Murray G, Marttila R, Haapea M, Rannikko I, et al. Lifetime antipsychotic medication and cognitive performance in schizophrenia at age 43-years - the northern Finland birth cohort 1966. Eur Psychiatry. 2015;30:271.

[61] Frances R. Long-term antipsychotic treatment and brain volumes: a longitudinal study of first-episode schizophrenia. Yearbook of Psychiatry and Applied Mental Health. 2012; 2012:130-2.

[62] Dorph-Petersen K, Pierri J, Perel J, Sun Z, Sampson A, Lewis D. The influence of chronic exposure to antipsychotic medications on brain size before and after tissue fixation: a comparison of haloperidol and olanzapine in macaque monkeys. Neuropsychopharmacology. 2005;30(9):1649-61.

[63] Pramyothin P, Khaodhiar L. Metabolic syndrome with the atypical antipsychotics. Curr Opin Endocrinol Diabetes Obes. 2010;17(5):460-6. 